\title{
Artigos
}

\section{A compreensão de relações familiares pelas crianças em situação de brincadeira em contexto de educação infantil3}

\begin{abstract}
Resumo: O artigo discute as compreensões das relações familiares que as crianças expressam em situação de brincadeira com parceiros de mesma idade em contexto de educação infantil. Essa discussão ocorre a partir da revisitação de alguns episódios de brincadeira estudados em pesquisa de mestrado (MAYNART, 2010), que buscou compreender a importância da brincadeira para a constituição da identidade da criança na perspectiva de Henri Wallon. A revisitação dos dados da pesquisa, a partir de uma ampliação de referenciais teóricos, traz novos elementos que realçam o complexo processo de significação que ocorre na cultura de pares em contexto de educação infantil. Considerando o brincar como um espaço privilegiado para a investigação de processos de construção de significados, os episódios selecionados revelam que o processo de compreensão de relações familiares se dá no entrejogo de modos de agir, pensar e sentir individuais e o sistema de crenças e teorias do mundo simbólico-cultural e passa, necessariamente pelas interações sociais com o outro.
\end{abstract}

Palavras-chave: Processos de significação; Cultura de pares; Educação infantil; Relações familiares.

\section{The understanding of family relationships by children in play situations in the context of early childhood education}

\begin{abstract}
This paper discusses the understandings of family relationships that children express in play situations with peers of the same age in the context of early childhood education. This discussion takes place from the review of some episodes of play studied in masters research (MAYNART, 2010), which sought to understand the importance of the play to the constitution of the child's identity from Henri Wallon's perspective. The review of the research data, based on an extension of theoretical references, brings new elements that highlight the complex process of signification that occurs in the culture of pairs in the context of early childhood education. Considering play as a privileged space for the investigation of meaning-making processes, the selected episodes reveal that the process of understanding family relationships occurs in the interplay of individual ways of acting, thinking and feeling, and the system of beliefs and theories of the symbolic-cultural world, which necessarily occurs through social interactions with the other.

Keywords: Meaning making; Peer culture; Early childhood education; Family relationships
\end{abstract}

\footnotetext{
1 Doutora em Educação pela Faculdade de Educação da USP (1997) e pós-doutora em Psicologia Social no Laboratório de Psicologia Social da Universidade Aix-Marseille, França (2011). Professora associada da Universidade Federal de Alagoas, pesquisadora associada da Fundação Carlos Chagas, líder do Grupo de Pesquisa "Educação Infantil e Desenvolvimento Humano", vinculado ao Programa de Pós-graduação em Educação da UFAL. E-mail: lenirahaddad@gmail.com

2 Doutoranda em Educação pela Universidade Federal de Alagoas. Mestre em Educação pela mesma Universidade. Professora Assistente da Universidade Federal de Alagoas, Campus Arapiraca. Membro do Grupo de Pesquisa Educação Infantil e Desenvolvimento Humano - UFAL. E-mail: renatamaynart1986@gmail.com

${ }^{3}$ Versão preliminar deste artigo foi apresentada na 35 Reunião Anual da Associação Nacional de Pós-Graduação e Pesquisa em Educação (Anped), em 2012.
} 


\section{Introdução}

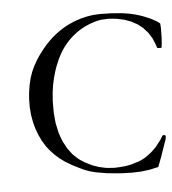

onstruir uma compreensão de sociedade, de como as pessoas se relacionam, exercem múltiplos papéis e estabelecem redes sociais, pode parecer um processo fácil ao olhar do adulto, mas é altamente complexo para a criança que está em pleno processo de desvendar os mistérios que circundam o mundo social. Dentro desse complexo mundo estão as relações familiares e de parentesco que se constituem na conjugação de consanguinidade, afinidade ou proximidade e variam no tempo e espaço e entre as diversas culturas existentes. De forma geral, as relações familiares e de parentesco configuram uma organização de papéis, ações e relações que são específicos, ou seja, pressupõe que cada figurante, seja pai, mãe, tio, tia, avô, avó, filho, filha, cunhada, cunhado, genro, nora, enteado etc. possua atributos que os definem e os diferenciam. Como as crianças constroem a compreensão das relações de parentesco em interação com seus pares, como a expressam e que sentido dão aos diversos papéis que as constituem compõem o objeto desse artigo.

Essa questão será discutida a partir de episódios de brincadeira de crianças de cinco anos em contexto de educação infantil em que as relações familiares e de parentesco ocupam tema central. Esses episódios foram extraídos de uma pesquisa de mestrado (MAYNART, 2010) que buscou investigar a importância da brincadeira na construção da identidade da criança, em que se observou sistematicamente crianças de 3, 4 e 5 anos brincando em um ambiente estruturado para tal. A reincidência do tema na brincadeira, especialmente entre o grupo de crianças de 5 anos, e sua ocorrência em contexto de educação infantil, nos motivou a revisitar as análises a partir de um referencial teórico mais alargado que aborda os processos de construção de significados.

Alguns pressupostos marcam o ponto de partida desse trabalho. A compreensão que os seres humanos têm do mundo social não é dada e sim construída nas relações sociais que estabelecem com o(s) outro(s). Produzir significado "é um fenômeno culturalmente mediado que depende da existência de um sistema simbólico partilhado" (BRUNER, 1997, p.76). Tais elementos, definidos por Carvalho e Pedrosa (2002, p. 183) como macrocultura compartilhada, são trazidos pelas crianças para a microcultura do grupo de brinquedo, o que o caracteriza como um espaço propício para a transmissão da cultura, uma vez que "as crianças assumem também um papel ativo em sua transmissão para os parceiros". Para as autoras, a presença da macrocultura no grupo de brinquedo revela-se também "através de papéis e valores, na formulação de regras baseadas em conhecimento social ou na recusa de papéis menos valorizados socialmente pelas crianças que lideram uma brincadeira" (CARVALHO E PEDROSA, 2002, p. 184).

Nas discussões acerca de compartilhamento de significados em situação de faz de conta, Coelho e Pedrosa (2012, p. 59-60) indicam que por meio de recursos da brincadeira de faz de conta, com a transformação de objetos do meio físico, a representação de personagens, gestos, palavras, posturas etc., 
as crianças retomam significados que já experienciaram, ao passo que constroem novos que fazem sentido no momento do seu processo interacional, sendo os objetos e as ações reais subordinadas ao campo do significado.

Para Wallon (2007, p. 62), o brincar se explica pela necessidade da criança de agir sobre o mundo exterior (das pessoas e dos objetos) "para adequar os recursos dele aos recursos próprios e para assimilar de maneira cada vez mais estreita partes mais extensas desse mundo". Assim, a brincadeira encontra fundamento e inspiração na cultura, a qual instiga à atividade de um ser, seus recursos, seus objetos e seus temas. Compreende-se, pois, que o brincar é uma forma de a criança trazer a cultura, as relações e as regras sociais à sua compreensão de mundo. Um dos recursos mais importantes que se utiliza como forma de se apropriar do mundo que a rodeia é a imitação, elemento primordial que possibilita a brincadeira de faz-de-conta, assim como a representação. A criança tenderá a imitar situações cotidianas, relacionadas a pessoas que tenha algum significado para ela. Neste ato, copia modelos que presencia, porém não de forma passiva, sua agência se manifesta no ajuste e execução do observado.

Oliveira (2011, p. 70) ressalta que os papéis são assumidos por indivíduos na busca por dar às circunstâncias concretas um sentido de acordo com as interpretações que formulam em relação a elas. Nesse sentido, a realidade psicológica de cada ser é colocada como narrativa e dinâmica, introduzida nos contextos histórico, político, cultural, social e interpessoal. Nas situações em que são criados, os papéis são de conhecimento compartilhado pelos membros da cultura, podendo ser adotados, previstos, atualizados e enriquecidos. No instante em que os papéis são assumidos, os indivíduos criam um enredo por meio de gestos e palavras, embate e encontro de subjetividades em constante formação. Jogos de papéis são criados tanto na interação adulto-criança quanto na interação criança-criança. Eles têm uma enunciação dinâmica por ser uma atividade intersubjetiva cuja eficácia é garantida pela rede de relações sociais que a instaura e que, ao mesmo tempo, lhe dá sentido (OLIVEIRA, 2011, p. 72). Neste jogo, diversos elementos, como objetos, adereços, gestos, posturas, sons, palavras, fazem o cenário e personagens que medeiam os enredos. Oliveira (2011) afirma que a matriz social em que a criança é introduzida desde o nascimento é que vai gerar significados que são atribuídos e assumidos, ao mesmo tempo em que são negados e recriados na interação devido ao confronto de papéis presentes nos processos que possibilitam dar sentido a si mesmo, ao outro e à situação como um todo.

Partindo da perspectiva de que o brincar possibilita à criança estar em constante interação com o outro, Corsaro $(2009,2011)$ traz importantes contribuições acerca da brincadeira de papéis na perspectiva da cultura de pares. Cultura de pares é definida pelo autor como um "conjunto estável de atividades ou rotinas, artefatos, valores e interesses que as crianças produzem e compartilham na interação com as demais" (CORSARO, 2011, p. 128).

Para o autor a produção da cultura de pares pela criança não é uma questão de simples e pura imitação, pois estas apreendem de forma criativa informações que captam do mundo adulto para poder produzir suas culturas próprias e singulares. Neste processo de reprodução criativa Corsaro (2007, p. 275) ressalta que "qualquer grupo de pares particular (que é um grupo coletivo de crianças que produz culturas 
de pares locais) representará uma geração particular num período histórico particular". Sobre este fato, leva-se em consideração o momento histórico de cada época, vivenciado de forma diferente por gerações. $\mathrm{O}$ autor defende que

[...] a apropriação e o enriquecimento de modelos adultos pelas crianças se referem primariamente a status, poder e controle. Ao assumir papéis adultos, as crianças adquirem poder (são "emponderadas"). Elas utilizam a licença dramática da brincadeira imaginativa para projetar o futuro - a época em que terão poder e controle sobre si mesmas e sobre os outros (CORSARO, 2009, p. 34).

Em outras palavras, as crianças trazem para a brincadeira o modelo de adulto que tem conhecimento: aquele que manda, e as crianças, aquelas que recebem a ordem. Observa ainda que este tipo de jogo possibilita que estas últimas experimentem como os diferentes tipos de papéis sociais agem e se relacionam entre si. Em suas pesquisas com crianças, observou que o tema mais comum nas brincadeiras de papéis de crianças na faixa etária de dois a cinco anos volta-se às expressões de poder, ou seja, as crianças trazem para a brincadeira as situações em que os adultos lhe impõem algum poder. Corsaro (2009, p. 36) ressalta ainda que "no jogo sociodramático as crianças desfrutam a assunção e a expressão de poder", através dos papéis hierárquicos e traz um episódio a título de ilustração do que vem a ser estes papéis hierárquicos na brincadeira, referindo-se a crianças que brincam de escola, numa situação em que uma delas assume o papel de professor, sem nunca ter frequentado escola. $\mathrm{O}$ meio cultural se encarrega de trazer estas informações para as crianças, seja através da televisão, ou de alguma situação entre adultos que presenciou. Neste caso, as crianças apresentam a informação, a imagem do que é ser professor que possui: professores são poderosos e dizem às crianças o que elas devem fazer.

Outro aspecto trazido pelas crianças para a brincadeira, enfatizado pelo autor é o gênero, ou seja, o comportamento das meninas e dos meninos e a forma como estes papéis são ou não estereotipados por gênero. Na perspectiva do autor, as crianças não aceitam ou não compartilham simplesmente esses estereótipos do mundo adulto, mais do que isso parecem desafiá-los e refiná-los ao seu modo. Um dos exemplos relacionados à concepção de gênero fornecido pelo autor é o episódio dos "dois maridos", em que um dos meninos que estava fazendo papel de gato desiste do papel e o menino que assumia papel de marido sugere que ele seja um segundo marido, "pois precisam de dois maridos". A menina que era a esposa parece não se sentir confortável com a solução e não a aceita, afirmando não poder ter dois maridos por ter uma avó. Ao final, ela resolve o problema tornando-se um gatinho (CORSARO, 2009, p. 39). De maneira ampla, o jogo de papéis é, na perspectiva do autor diversão, improvisação, imprevisibilidade e riqueza por possibilitar oportunidades de reflexão e aprendizagem. Corsaro (2009, p. 40) afirma que "o jogo de papéis envolve mais do que a aprendizagem de conhecimentos sociais específicos; envolve também aprender a relação entre contexto e comportamento". Ao fazer referência a Bateson (1956, apud CORSARO, 2009, p. 41), concorda que ao brincar de papéis, além de aprender a respeito da posição social específica daquele papel, a criança aprende também que existem papéis. 
Todos esses argumentos nos levam a acreditar que a observação de crianças em situação de brincadeira entre pares permite capturar e compreender os sentidos atribuídos às normas, regras e papéis sociais que trazem, em especial os sentidos que atribuem às relações de parentesco, objeto deste artigo.

\section{Sobre o método}

Os episódios analisados a seguir foram extraídos do banco de dados da pesquisa de Maynart (2010) que buscou compreender, à luz da teoria de Henri Wallon, o processo de constituição do eupsíquico da criança e sua relação com a brincadeira. A pesquisa envolveu a observação sistemática de situações de brincadeira entre crianças em uma instituição de educação infantil situada na Universidade Federal de Alagoas na cidade de Maceió, que atende crianças entre 1 e 5 anos. Três grupos de crianças de 3, 4 e 5 anos foram formados com 5 crianças da mesma idade, de ambos os sexos, em cada grupo. Os dados foram gerados em uma sala especialmente organizada para suscitar a brincadeira de faz de conta. Para isso, foram organizadas nesta sala quatro áreas de interesse: casinha, beleza e fantasia, brinquedos e blocos e leitura. Em cada uma delas foram disponibilizados materiais e brinquedos correspondentes ao que cada área representa. A área da casinha foi composta de móveis e objetos que remetem à sala e cozinha. A área da fantasia e da beleza dispunha de uma arara com várias fantasias e adereços. A área dos brinquedos e blocos foi formada com blocos de madeira, jogos variados etc. Para área da leitura organizou-se um canto com tapete, almofadas, pufes e dois mostruários pendurados na parede com livros de histórias infantis. As sessões foram videogravadas e tiveram duração média de 20 a 25 minutos cada. Partindo da perspectiva de que a instituição de educação infantil é um lugar privilegiado para a realização de estudos com crianças com bases observacionais, o procedimento de análise foi o da observação sistemática de momentos de brincadeira entre as crianças de cada grupo que foram videogravadas, seguidas da seleção de episódios que foram recortados e transcritos para posterior análise microgenética.

\section{Análise dos episódios}

Os episódios descritos a seguir referem-se ao grupo de crianças de 5 anos e foram extraídos de duas sessões de videogravação que trazem situações de brincadeiras que envolvem relações familiares e de parentesco. São cinco episódios no total, sendo os quatro primeiros capturados na mesma sessão e o quinto após 16 dias.

A descrição e análise das interações e negociações que se dá entre os pares nos permitem uma aproximação deste complexo processo de construção de significados pela criança dos papéis familiares, que envolvem as relações de parentesco. 
Episódio 1: Eu não sou o titio não, eu sou o irmão!

Crianças envolvidas: Giovana (5;9), Anarele (5;9), Marcus Paulo (5;6) e Nilton $(5 ; 4)$

\begin{abstract}
Marcus Paulo está deitado no colchonete da área da leitura. Nilton, com um violão na mão, se aproxima e diz: "Eu sou filho do Marcus. Eu ganhei uma medalha, não foi Marcus?" Este responde "foi". Levanta, vai para a cozinha, pega o ferro de passar roupas e diz a Nilton: "vou passar a roupa pra gente... Pra amanhã você ir pra escola, viu?" e "passa" a roupa com o ferro em cima da mesa. Giovana se levanta da cama onde estava deitada, olha para Marcus Paulo e diz: "papai". Este responde: "sim, filha". Giovana continua: "o quê que eu vou usar para ir pra escola?” Nilton responde: "vá com esse vestido, né?" Giovana faz cara de brava, corre para perto de Nilton, fecha os punhos e diz elevando os braços: "mas... Tio!” Marcus Paulo fala: "é seu irmão ele. É seu irmão, menina”. Giovana responde: "sim". Anarele ao ouvir o diálogo diz a Nilton: "vou ligar para o seu pai viu, filho?" e Marcus Paulo diz: "não, ele é o meu filho", referindo-se a Nilton. Anarele responde: "não, tem que ser o do pai verdadeiro". Marcus Paulo responde: "não, mas é meu". Giovana em frente ao espelho e balançando o vestido diz: "ai o quê que eu vou usar meu... Ob papai, cadê aquela máquina que você me deu?" Com as duas mãos na cabeça, roda em círculo e diz: "cadê a máquina, papai, papai, papai... cadê a máquina papai??" Baixando o tom de voz. Ao ver que Nilton está sentado com a câmera, Giovana diz: "ei, aqui está a máquina” e tira a câmera de Nilton. Marcus Paulo compreendendo que a máquina que "a filha" procura é o ferro de passar roupas, eleva-o na direção de Giovana e diz: "a máquina né, de passar? Ó aqui filha". Giovana responde indicando para o objeto que está na mão dela: "aqui está a máquina!” Coloca a câmera no olho, simulando tirar uma foto de Nilton, e diz: "titio". Este faz pose para a foto, colocando a língua de fora e diz: "eu não sou o titio não, eu sou o irmão". Marcus Paulo fala: "ele é seu irmão". Giovana continua: "tá bom, titio". Nilton reafirma: "sou seu irmão eu, sou seu irmão". Giovana diz: "tá". Em tom bem exagerado, balançando o vestido e em voz alta Giovana fala a Nilton: "î irmão cadê o meu colar?" Marcus Paulo é quem responde: "sei lá, deve tá com sua irmã", referindo-se à boneca. Ao perceber que Nilton está com umas medalhas no pescoço, Giovana se põe a correr atrás dele. Nilton foge e ela continua a correr atrás dele. Enquanto correm, sorriem o que sugere uma brincadeira de perseguição entre dois irmãos. Marcus Paulo diz: "é medalha, é medalha, minha filha " como se estivesse lembrando a filha que o que ela procura é o colar. Logo "os irmãos" param de correr.
\end{abstract}

Nesta primeira cena Marcus Paulo concorda em assumir o papel de pai que lhe é atribuído por Nilton como filho, respondendo com a ação de passar a roupa do "filho" para este ir à escola. A compreensão de pai revelada pelo menino se aproxima daquela que cuida dos filhos e dos afazeres domésticos, sem necessariamente incorporar os estereótipos de gênero que separam as funções que pertencem a um pai e a uma mãe. A afinidade que desenvolve com Nilton (pai e filho, respectivamente) traz uma relação de cordialidade, sem expressão explícita de poder. Ao tempo que atribui para si o papel de pai de família, Marcus Paulo também organiza a brincadeira e os demais papéis. Aceita que Giovana seja a filha, porém, quando Anarele diz ser a mãe de Nilton, não a acolhe e reafirma a paternidade em relação a Nilton. Giovana, que se insere na brincadeira como filha pergunta ao "pai", o que deverá usar para ir à escola, ou seja, utiliza-se do mesmo argumento que deu concretude ao parentesco entre Nilton e Marcus Paulo. De início, Giovana revela certa incompreensão quanto às definições de papéis e acaba por chamar Nilton de tio, quando naquele contexto, já que este que iniciou a brincadeira chamando Marcus Paulo de pai, esta e Nilton deveriam então ser irmãos. Marcus Paulo rebate a fala da colega: "é seu irmão, ele. É seu irmão, menina", numa atitude que sugere que esteja querendo corrigir Giovana. Afirma-se assim a configuração familiar, cujas regras não parecem ainda claras. Giovana, no seu papel de filha parece testar a todo instante as atitudes de pai desempenhadas por Marcus Paulo, recorrendo a ele seja para encontrar objetos perdidos, resolver conflitos e situações entre irmãos, ou pedir auxílio no uso da roupa. A 
compreensão de filha revelada pela menina é que deve ser sempre atendida pelo pai e auxiliada em suas necessidades. Para Nilton e Marcus Paulo, que iniciaram a brincadeira com a atribuição e aceitação de papéis, os papéis que cada um deverá desempenhar, assim como a irmandade de Nilton e Giovana estão claros. Mas para Giovana ainda não está. A referência a Nilton como tio por repetidas vezes pode tanto expressar uma confusão de papéis ou uma provocação. Parece que a aceitação da condição de irmã de Nilton só se concretiza posteriormente, no momento em que Giovana constata que Nilton está com uma medalha no pescoço e lhe surge a ideia de que tal objeto é o colar que tanto procurava. Para concretizar esta ideia, pergunta a Nilton, seu irmão, onde está o colar e passa a correr atrás do "irmão" para pegá-lo. A situação criada pela menina é de dois irmãos que querem o mesmo objeto e Marcus Paulo, no papel de pai e no exercício de seu poder hierárquico que desempenha sobre os filhos, deverá resolver a situação, conforme foi feito na brincadeira.

Episódio 2: E você, cale boque.

Giovana finge telefonar para alguém. Anarele diz: "filha, quem mandou você mexer no meu telefone?". Giovana larga o telefone e simula passar perfume. Anarele tenta tomar das mãos de Giovana o frasco de perfume que ela simula passar. Esta então diz: "mamãe, me dá o meu perfume, en já vou sair toda chique, toda bela e toda bonita, nem me faça mais pergunta". Anarele grita: "fillha, pare com isso!". E sai com a bolsa pendurada e a empurrar o carrinho de bebê. Giovana fala ainda mais alto e faz gestos com as mãos em frente à Anarele: "olhe como fala com a sua filha, com a sua filha...". Anarele responde: "e você, cale boque" (expressão que utiliza para falar: cale a boca).

Em sequência ao episódio anterior, Giovana permanece no papel de filha e Anarele desempenha o de mãe. Esta última assume uma postura de mãe autoritária que exerce poder sobre a filha. As relações de poder que os papéis familiares podem representar, como indicado por Corsaro (2009), estão postas. No papel de mãe, Anarele pede várias vezes para a "filha" se calar, assim como no momento em que solicita que Giovana pare de falar em tom de voz alto com ela, já que ela era sua mãe. Ela assume o papel de uma mãe autoritária com atitudes impositivas, que expressa que uma filha ou um filho deve respeito à mesma. O exercício de poder realizado por Anarele pode ser percebido ainda quando a filha (Giovana) pega o telefone e, em seguida, o perfume e como mãe tenta impedi-la de fazer algo sem ter the pedido autorização. Giovana, apesar de estar em uma situação inferior à colega na escala hierárquica, revida o que Anarele diz ao garantir, ao invés de pedir, que irá sair e dizer que a "mãe" não lhe faça mais pergunta, o que sugere que não lhe deve satisfação. Anarele, por sua vez, parece não se conformar com a atitude da filha e como forma de elevar sua posição, aumenta o tom de voz e ordena que a "filha" pare, neste caso de rebater o que ela diz. Giovana, mais uma vez, se impõe e fala ainda mais alto com a sua "mãe" invertendo a expectativa de obediência que supostamente uma filha teria com uma mãe. Tem-se assim um confronto de perspectivas de papéis no âmbito das hierarquias familiares: Anarele assume uma relação hierárquica de poder, impondo sua autoridade de mãe sobre a filha ao insistir que a filha lhe obedeça e cale a boca; 
Giovana, por sua vez, enfrenta a autoridade da mãe, de forma destemida, pois levanta o dedo e aponta para aquela no instante em que fala com o tom de voz elevado.

Cena 3: Então cuide aí da nossa filha que eu vou trabalhar.

Giovana pula no colchonete da área da leitura e Marcus Paulo diz: "sai da minha cama minha filha". Giovana diz: "e você, papai?" Anarele fala: "cale boque filha, oxe!" Marcus Paulo olha para a boneca que está no carrinho que Anarele segura e pergunta: "é nossa filha?" Anarele responde: "ê". Marcus Paulo diz: "é minha"e Anarele responde: "de nós dois, en sou a mãe" [...] Marcus Paulo que estava deitado na sua "cama" levanta-se, pega as "ferramentas" que o filho tinha entregue a ele, e diz à Anarele: "então cuide aí da nossa filha que eu vou trabalhar". Dirige-se para a área dos brinquedos e Anarele o segue respondendo: "não, não, não, não, de jeito nenbum, vai não". Este volta para a área da cozinha e diz: "já terminei meu trabalho", colocando as "ferramentas" em cima da mesa.

Mais uma vez, a expressão de poder prevalece nas brincadeiras que envolvem a compreensão das relações de parentesco. À medida que Marcus Paulo vê a filha no colchonete, e pede que esta "saia" de sua cama, utiliza-se da condição hierárquica que se encontra para exercitar seu papel e obter direitos a quem está em uma situação inferior a ele. Anarele, que na cena anterior buscou afirmar seu poder de mãe diante de Giovana, parece encontrar na atitude de Marcus Paulo um meio para se impor à Giovana e reafirmar sua condição de mãe. Ao acordarem os papéis de pai e mãe, Marcus Paulo e Anarele trazem as relações de gênero que permeiam a situação de brincadeira. No instante em que Marcus Paulo diz a Anarele que cuide da filha que irá trabalhar, parece revelar sua compreensão das relações que um casal desenvolve em grande parte das famílias brasileiras: a mãe cuida dos filhos, enquanto o pai vai trabalhar. Anarele, que parece querer se impor também ao pai de sua filha, fala por repetidas vezes "de jeito nenhum”, demonstrando não aceitar essa condição do pai trabalhar e a mãe cuidar da filha. Vê-se neste episódio que pai e mãe, especialmente esta última, expressam sua autoridade por meio de usos de imperativos e entonações fortes, como Anarele neste e no episódio anterior. Parece, conforme sugere Corsaro (2009, p. 39) que "elas querem criar e compartilhar emocionalmente o poder e o controle que os adultos têm sobre elas".

Cena 4: Pai faz um suquinho pra mim, por favor?

Marcos Paulo dirige-se ao armário e fala a Giovana: "filha vou fazer sua comida, viu?" Esta pega a máquina fotográfica com a qual brinca, entrega nas mãos de Marcus Paulo, senta-se à mesa e diz: "pai cadê men suco? Pai faz um suquinho pra mim, por favor?". O menino responde: "tá, vou fažer", colocando a câmera na mesa. Pega o liquidificador e "faz" o suco da "filha". Logo "derrama" o "suco" na taça que está próxima à Giovana produzindo um som onomatopéico: "txii... Se quiser mais tem na geladeira, viu minha filha?" esta "tomando" o suco responde afirmativamente: "bunrum". Anarele se aproxima, observa os dois e diz para Nilton: "en quero Nescau, já pedi". Marcus Paulo responde: "tá, vou fazer". Pega o liquidificador, balança-o, "derrama" o conteúdo em outra taça e diz para Nilton: "já fir filho, já fir pra você", pega a câmera fotográfica e avisa a Giovana: "agora eu vou sair, viu? Obedeça a sua mãe, vou sair pra tirar foto" e retira-se da área da cozinha.

Assim como em todas as cenas, os papéis das brincadeiras estiveram voltados para as relações de parentesco e Marcus Paulo mantém o papel de pai. Pensando-se na estrutura familiar de outrora e da 
atualidade, na maioria das famílias brasileiras o pai continua sendo o provedor da família, portanto, aquele que trabalha fora de casa e por isso não assume os afazeres domésticos junto aos filhos como fazer lanche, passar roupa, etc. Nas cenas apresentadas, Marcus Paulo parece se contrapor a tais estereótipos de gênero e continua a agir conforme um modelo de pai que faz a comida dos filhos, atende a seus pedidos, arrumao para ir à escola, passa a roupa, assumindo uma função de cuidar com muito mais amplitude e propriedade do que Anarele, que representa nesse cenário a mãe, aquela que culturalmente se encarrega de tais tarefas. Como se revelou um "pai" esmerado, carinhoso e cuidadoso na brincadeira que organizou, possivelmente isto possa ter incitado em Giovana um movimento de querer ser "cuidada" por este pai, quando pergunta ao "pai" o que irá vestir, em seguida pergunta pela sua câmera fotográfica, ou quando pede para o pai lhe fazer suco.

Estes elementos permitem dizer que a compreensão das relações familiares, no caso, especificamente da relação entre pai e filhos desempenhados por essas crianças envolve não apenas a assunção de papéis complementares, de pai, mãe, filho, filha, mas a apreensão de uma série de tarefas de cuidado que pressupõe reciprocidade: cuidar e ser cuidado. Há também forte relação de autoridade e poder, especialmente na escala hierárquica pais e filhos e, nas situações aqui relatadas, entre mãe e filha. Destaca-se a recomendação do pai Marcos Paulo a sua filha Giovana ao se despedir para ir ao trabalho: Obedeça a sua mãe, reafirmando a autoridade da esposa/mãe para com a filha.

\title{
Cena 5 - Tio também pode ter filho!
}

Crianças envolvidas: Giovana (5;9), Anarele (5;9), Cláudia(5;5), Marcus Paulo (5;6) e Nilton (5;4).

\begin{abstract}
Anarele, Cláudia e Giovana estão vestidas com roupas da área da fantasia. Cláudia segura o carrinho de bebê com a boneca. Marcus Paulo sentado à mesa olha para as colegas e, com o dedo indicador levantado, indaga: "quem é a tia? Que eu sou o tio". Levanta, toca na cabeça de cada colega e diz os papéis de cada um: "mãe (para Anarele), babá (para Giovana), tia (para Cláudia) e meu fillhinho (para Nilton)". Giovana diz: "eu sou a babá? Eu sou a babá do Nilton!”. Anarele, diz: "e eu sou a mãe do Nilton". Giovana abre um lenço da área da fantasia e diz com empolgação: "olha, eu vou usar!" E coloca em seu pescoço. Marcus Paulo retorna para sua cadeira, senta-se. Em seguida, levanta-se e diz se reportando à pesquisadora, que permanece neutra: "ô tia eu sou prefeito. Cadê o celular, que eu preciso do celular. Cadê o celular tia?”. Dirige-se para a área de brinquedos e blocos para procurar o celular, pega o aparelho de telefone fixo e leva para a mesa do computador em que se encontrava sentado. Nilton toca um violão e pergunta aos colegas: "quem quer fazer uma banda comigo?" Marcus Paulo fala: "era o men filho que, era de ban... [banda] teu brinquedo era na banda. Tu brincava de banda, aqui no meu trabalho". Tira o telefone do gancho e finge discar para alguém. Diz algo que não se consegue compreender e finaliza: "alô, sim, xau". Passa o telefone para Nilton que está sentado ao seu lado e diz: "mamãe quer falar com você. Mamãe". Nilton larga o violão que estava a tocar em cima da mesa, pega o telefone e diz: "mamãe, mamãe, mamãe..." Solta o telefone fora do gancho em cima da mesa e retoma seu violão. Marcus Paulo levanta da cadeira, e sai em direção à cozinha, se aproxima de Cláudia e lhe diz: "menina, o nosso filho chamou por você no celular". Anarele, que está toda enfeitada de badulaques, intervém e diz: "eu sou a mãe". Marcus Paulo retruca: "você não é a mãe". Anarele responde: "sou". O menino continua: "você é a mãe de outra pessoa. Eu sou tio". Aponta para Nilton e diz: "tio também pode ter filhos". Anarele diz: "não, só mãe". Marcus Paulo discorda: "ah não!" Cláudia que está a mexer nas panelas em cima do fogão diz pegando no carrinho em que está a boneca: "eu sou a mãe dela”. Marcus Paulo diz: "ela já é”, reafirmando que Cláudia é a mãe. Giovana
\end{abstract}


diz: "en sou a cabeleireira". Marcus Paulo insiste: "a Clándia já disse que já era, não foi Clándia? É a Cláudia que é a mãe dos meus filhos".

Neste episódio, assim como nas situações que lhe antecederam, a brincadeira surge a partir de um convite, desta vez, feito por Marcus Paulo, a brincar com os papéis familiares. No instante em que pergunta quem será a tia e afirma que será o tio, o menino parece acreditar que um tio necessita de uma tia para completar as relações de parentesco que está em sua mente. Ele sinaliza que quer desenvolver uma brincadeira que envolve uma relação conjugal, porém, diferentemente das cenas anteriores em que tais relações eram expressas pelos papéis de pai e mãe, este a representa nomeando a si e procurando uma colega para serem, respectivamente tio e tia. Tais papéis se modificam apenas no título de parentesco no que diz respeito a cenas anteriores, pois o menino continua a desempenhar o papel de pai e uma relação conjugal. A diferença é que ao invés de pai da família agora é o tio da família. Além disso, designa outros papéis que complementam a estrutura familiar: o papel de mãe para Anarele, de babá para Giovana, de tia para Cláudia e filho para Nilton. O papel de babá é novo, até o presente momento não havia aparecido nas brincadeiras. Apesar de não ser um papel de parentesco que se dá por consanguinidade, se faz presente no seio das famílias que as crianças têm referência. Giovana, que antes era filha, parece ficar surpresa com a nova atribuição "Eu sou a babá??", mas rapidamente se situa na configuração familiar, associando seu papel aquele que foi designado a ser filho. "Sou babá do Nilton" e anuncia que vai usar um lenço, como que para dar um diferencial, uma marca ao novo papel. Anarela, que não tinha recebido nenhum papel, se insere na brincadeira como mãe de Nilton.

A configuração familiar está posta, mas Marcus Paulo atribui a si mais um papel: o de prefeito. Para este papel se instala em um "escritório" que organizou com uma mesa e teclado do computador e materiais como canetas, lápis e o aparelho de telefone fixo. Observa-se que mesmo sendo o prefeito, não se exime dos demais papéis familiares. Incorpora a banda do filho ao seu escritório, coloca o filho em contato telefônico com a mãe e reclama desta (Cláudia) a falta de atenção para o papel que lhe fora atribuído: tia e mãe de Nilton. Entretanto, um impasse se coloca no momento em que Anarele afirma ser a mãe na brincadeira e percebe que seu papel está ameaçado. A menina parece não se aperceber que o papel designado a Cláudia como tia, lhe dá autoridade de conjugue, e passa a disputar com ela a maternidade de Nilton. Afinal, quem é mãe de Nilton? Na sessão anterior o próprio Marcus Paulo havia designado este papel para ela. Nesta sessão, Marcus Paulo atribui o papel de mãe de seus filhos a Cláudia, e informa que a colega pode ser a mãe de outros filhos, mas não do dele. Para Marcus Paulo, a mãe de Nilton é Cláudia, portanto, se Anarele é mãe, ela é de outra pessoa. Ele é o tio, que “também pode ter filhos”. Novamente, duas perspectivas entram em conflito, pois as crianças parecem não compartilhar o mesmo significado sobre “ter filhos". Para Marcus Paulo, tio pode ter filhos porque um tio também pode ser pai. Neste caso, ele como tio e Cláudia como tia, têm filhos em comum. Para Anarele não, "só mãe" pode ter filhos, pois possivelmente, sua referência está associada tão somente ao parto e à maternidade. 


\section{Algumas considerações}

Nas brincadeiras que envolvem papéis familiares e relações de parentesco as crianças trazem elementos da macrocultura que funcionam como um substrato para o processo de produção de significados. A cada papel desempenhado associa-se funções, atribuições e regras que são realizadas, confrontadas, negociadas e ressignificadas no entrejogo de modos de agir, pensar e sentir de cada criança individualmente e o sistema de crenças e teorias do mundo simbólico-cultural e passa, necessariamente pelas interações sociais com o outro.

Nos referidos episódios as brincadeiras que trouxeram como temática as relações de parentesco constituíram um rico meio de estudo acerca das compreensões das crianças, da construção de significados sobre o papel de cada integrante de uma família. Por meio da brincadeira de faz de conta as crianças realizaram o exercício de reconhecimento dos papéis sociais que envolvem relações de parentesco, tais como: pai, mãe, filho(a), irmão(a), tio(a), sobrinho (a), bem como de papéis que não tem relação de parentesco, mas que de alguma forma faz parte de rotinas familiares, como por exemplo babá, por meio de enredos construídos que forneceram indícios de suas compreensões.

Tal compreensão não se dá de forma imediata, o que pode ser atestada nas situações em que as crianças não compartilharam dos mesmos significados. É na constante interação e negociação entre os pares que os papéis são ressignificados e testados à medida que as crianças criam situações e os exercitam.

$\mathrm{Na}$ brincadeira infantil as figuras de pai e de mãe encontram-se no topo de uma hierarquia e de autoridade, com isso, ao assumir tais papéis, as crianças reproduzem de forma interpretativa a autoridade para com as demais que desempenham papéis considerados secundários, como o de filhos. No processo de assunção de papéis e desempenho de ações associados a estes papéis as crianças não apenas mencionaram seus personagens, o que cada um iria fazer, mas revelaram como cada um deles age de acordo com suas compreensões pessoais, negociadas no grupo. Nestas circunstâncias revelaram suas compreensões acerca de família como aquela em que os filhos devem obediência aos pais, estes, por sua vez cuidam dos filhos, seja no âmbito afetivo, seja de subsistência; negociaram concepções a respeito do pai trabalhar e a mãe permanecer em casa, cuidando dos filhos, bem como revelaram compreensões de que o pai, figura masculina, pode cuidar, dar carinho, vestir e alimentar os filhos, tarefa ainda hoje mais delegada à mulher. É neste momento que a criança reproduz e negocia hierarquia, regras, papéis, testa ao experimentar modelos e organizações familiares.

Entende-se, pois que ao brincar, a criança reproduz e recria padrões de comportamento típicos do modelo de família do qual tem conhecimento e faz parte do seu meio cultural. O ambiente organizado e os materiais dispostos são propulsores da brincadeira, da assunção de papéis e da construção de enredos. Sobre esta perspectiva, pode-se dizer que, embora a brincadeira aconteça independente dos objetos, pois a criança possui uma motivação intrínseca para brincar, que é alimentada nas constantes interações que estabelece com o outro, um espaço intencionalmente estruturado para tal potencializa esta atividade. Entretanto, não é suficiente apenas a organização dos espaços e a diversidade de brinquedos e materiais. 
A discussão aqui realizada traz implicações diretas para se pensar a formação do(a) professor(a) da criança de 0 a 5 anos de forma a desenvolver a escuta e o olhar sensível para promover o protagonismo da criança e apoiar a sua participação, seus reais interesses, suas experiências, suas construções, compreendendo o lugar do brincar e seu papel diante dessa atividade. Uma formação que o instrumentalize quanto ao exercício da observação, registro, planejamento e avaliação, dentre outros aspectos da prática pedagógica que caminham na direção da consolidação de uma identidade específica e responsiva da educação da infância que vem se efetivando especialmente após a revisão das Diretrizes Curriculares Nacionais para a Educação Infantil (BRASIL, 2009). 


\section{Referências}

BRASIL. Ministério da Educação. Secretaria de Educação Básica. Diretrizes Curriculares Nacionais para a Educação Infantil. Brasília: MEC/SEB, 2010.

BRUNER, J. Actos de significação para uma psicologia cultural. Lisboa: Edições 70, 1997.

CARVAlHO, A. M. A. \& PEDrosA, M. I. Cultura no grupo de brinquedo. Estudos de Psicologia. Natal, 7: 1, p. 181-188, 2002.

COELHO, M. T. F. \& PEDROSA, M. I. Faz-de-conta: construção e compartilhamento de significados. In: OLIVEIRA, Z. M. R. (Org.) A criança e seu desenvolvimento: perspectivas para se discutir a educação infantil. São Paulo: Cortez, 2012.

CORSARO, W. Reprodução Interpretativa e cultura de Pares. In: Fernanda Müller, Ana Maria Almeida Carvalho (orgs.)Teoria e Prática na pesquisa com crianças: diálogos com Willian Corsaro. São Paulo: Cortez, 2009.

CORSARO, W. Sociologia da infância. Tradução de Lia Gabriele Regius Reis. Porto Alegre: Artmed, 2011.

MAYNART, R. C. A brincadeira e o processo de constituição do eu-psíquico da criança: implicações para a educação infantil. 152 f. Dissertação (Mestrado em Educação) - Universidade Federal de Alagoas, Maceió, 2010.

MÜLLER, F. Entrevista com Willian Corsaro. Educação \& Sociedade, ISSN 0101-7330, vol.28 no.98 Campinas Jan./Apr. 2007.

OLIVEIRA, Z. M. R. Jogos de papéis: um olhar para as brincadeiras infantis. São Paulo: Cortez, 2011.

WALLON, H. Psicologia e educação da infância. In: Tradução Ana Rabaça. Lisboa: Estampa, Lda., p. 9-21, 1975.

Psicologia e educação da infância.

WALLON, H. O brincar. In: A evolução psicológica da criança. Tradução Claudia Berliner; revisão técnica Izabel Galvão. São Paulo: Martins Fontes, p. 54-70, 2007 